\title{
World Journal of Impact of distance on postoperative follow-up in patients of pediatric surgery: a retrospective review
}

\author{
Meagan E Wiebe (D) , ${ }^{1}$ Anna C Shawyer ${ }^{2}$
}

To cite: Wiebe ME, Shawyer AC. Impact of distance on postoperative follow-up in patients of pediatric surgery: a retrospective review. World $\mathrm{Jnl}$ Ped Surgery 2020;3:e000195. doi:10.1136/wjps-2020-000195

Received 30 July 2020 Revised 6 November 2020 Accepted 10 November 2020
Check for updates

(C) Author(s) (or their employer(s)) 2020. Re-use permitted under CC BY-NC. No commercial re-use. See rights and permissions. Published by BMJ.

${ }^{1}$ Section of General Surgery, Department of Surgery, University of Manitoba, Winnipeg, Manitoba, Canada ${ }^{2}$ Section of Pediatric General Surgery, Department of Surgery, Children's Hospital Research Institute of Manitoba, University of Manitoba, Winnipeg,

Manitoba, Canada

Correspondence to Dr Meagan E Wiebe; wiebem25@myumanitoba.ca

\section{ABSTRACT}

Objective Centralization of medical services in Canada has resulted in patients travelling long distances for healthcare, which may compromise their health. We hypothesized that children living farther from a children's hospital were offered and attended fewer follow-up appointments.

Methods We reviewed children less than 17 years of age referred to the general surgery clinic at a tertiary children's hospital during a 2-year period who underwent surgery. Descriptive statistics were performed.

Results We identified 723 patients. The majority were male $(61 \%)$ with a median age of 7 years (range 18 days to16 years) and were from the major urban center (MUC) (56.3\%). The median distance travelled to hospital for MUC patients was $8.9 \mathrm{~km}$ (range $0.9-22 \mathrm{~km}$ ) vs $119.5 \mathrm{~km}$ (range 20.3-1950 km) for non-MUC patients. MUC children were offered more follow-up appointments ( $72.7 \%$ vs $60.8 \%, p<0.05)$. No significant differences existed in follow-up attendance rates (MUC $88.5 \%$ vs non-MUC $89.1 \%, p=0.84)$ or postoperative complications $(9.8 \%$ vs $9.2 \%, p=0.78)$. There were no deaths.

Conclusions Patients living farther from a hospital were offered fewer follow-up appointments, but attended an equivalent rate of follow-ups when offered one. Telemedicine and remote follow-up are underused approaches that can permit follow-up appointments while reducing associated travel time and expenses.

\section{INTRODUCTION}

Canadian healthcare has been centralized since the 1990s to improve outcomes and to decrease costs to the healthcare system. ${ }^{1}$ For pediatric surgical patients, centralization permits specialization of care, provision of care in proximity with prenatal diagnosis centers, and fostering of multidisciplinary connections for exploring fetal and neonatal surgical outcomes research. ${ }^{2}$

However, despite these advantages, the regionalization of care results in some patients living farther from pediatric hospitals and travelling greater distances for medical care. ${ }^{3}$ Canada has an area of 9.985 million $\mathrm{km}^{2}$ and 16 urban tertiary pediatric hospitals. ${ }^{45}$ Among Canada's population of approximately 36 million people, over $40 \%$
Key messages

What is already known about this subject?

- The centralization of healthcare in Canada has led to improved outcomes and decreased healthcare costs; however, now most patients must travel long distances to receive medical care, which may impact the level of care they receive.

\section{What are the new findings?}

- Patients who live farther from a pediatric hospital are offered fewer postoperative follow-up appointments yet attend a similar number of follow-up appointments compared with their urban counterparts when offered one.

\section{How might it impact on clinical practice in the foreseeable future?}

- This study highlights the need for an assessment of the importance of postoperative follow-up appointments in pediatric patients, the implementation of the findings in postoperative care pathways, and the incorporation of telemedicine and remote follow-up into practice for when postoperative follow-up is warranted.

are from rural areas or small towns, with longer distances to tertiary medical care. ${ }^{6}$ Discrepancies in healthcare usage based on one's proximity to services exist; people living closer use services more often. ${ }^{7}$ Additionally, distance to healthcare significantly impacts healthcare-related costs owing to increased travel and parking costs and to missed days at work and school. ${ }^{8}$

The Winnipeg Children's Hospital (WCH), located in Winnipeg, Manitoba, Canada, is one of the 16 pediatric surgery centers in the country. ${ }^{5}$ It provides healthcare to patients from the provinces of Manitoba, northwestern Ontario, and southeastern Saskatchewan, and from the territory of Nunavut, which includes a patient catchment area of more than 1.5 million individuals across more than 2.58 million $\mathrm{km}^{2}$ (figure 1). ${ }^{9-11}$ Patients must travel long distances for appointments, 


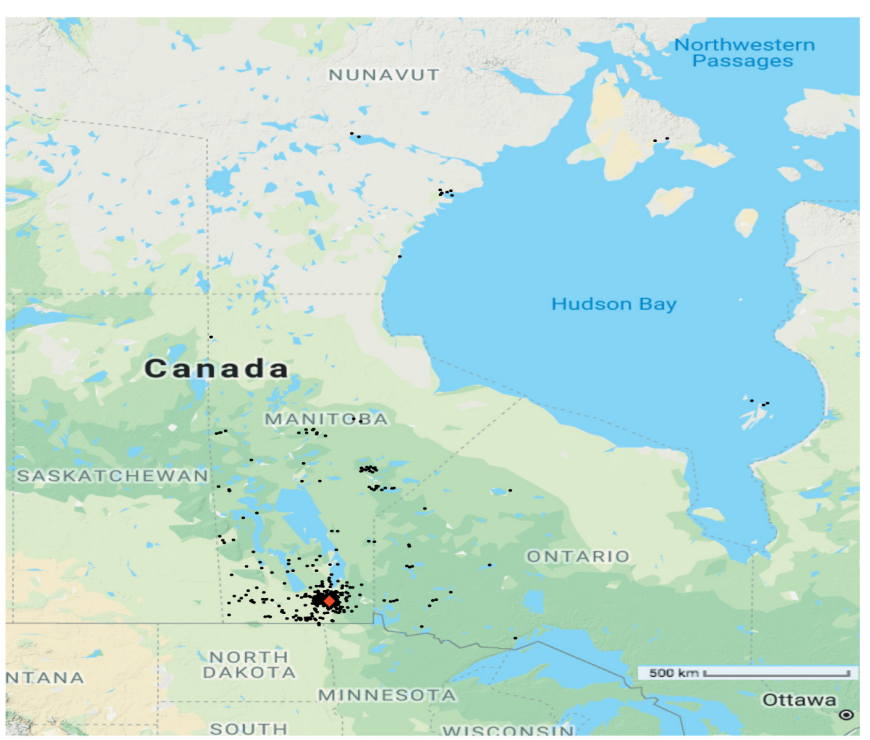

Figure 1 Map of Winnipeg Children's Hospital's catchment area showing the jittered location and distribution of our patient population. One black dot represents one patient and the red diamond denotes the location of Winnipeg Children's Hospital.

and some live in areas with limited access (eg, ice roads, boat, or float plane access only).

The purpose of this study is to determine if children under 17 years of age who are referred to the pediatric general surgery clinic at the $\mathrm{WCH}$ and who undergo an elective surgical procedure are offered and attend fewer postoperative follow-up appointments if they live farther from the hospital. Some patients may have additional needs that negatively impact the quality of care they receive such as the need for additional personal protection equipment, or a language barrier, or distance needed to travel to a medical appointment. We hypothesize that patients living farther are given fewer appointments and attend fewer appointments.

\section{METHODS}

Study design

A retrospective chart review was performed following ethics approval. We reviewed all children under 17 years of age referred as outpatients to the pediatric general surgery clinic at the WCH in Winnipeg, Manitoba, Canada, between 1 January 2016 and 31 December 2017, who underwent an elective surgical procedure. This included patients having surgery with an anticipated shorter length of stay ( $<48$ hours). It excluded patients with major neonatal surgical conditions and congenital malformations.

\section{Outcome variables collected}

A prepiloted data collection tool was used to retrieve deidentified variables including demographics, diagnostic results, surgical procedure performed, follow-up invitation and attendance, and postoperative complications.
Distance was defined as the distance in kilometers between the location of the first three digits of the patient's home postal code to the WCH using the Google Maps website (Google Maps JavaScript API V.3.37). Geographic region refers to the Manitoba Regional Health Authority in which the patient's hometown is located. For purposes of comparison, the data were divided into two groups: patients from Winnipeg (major urban center (MUC)) and patients from outside of Winnipeg (non-MUC). Patients from MUC included everyone from within the Winnipeg Regional Health Authority, and nonMUC patients included those from the other Manitoba Regional Health Authorities and patients from outside of Manitoba. The non-MUC group was further subdivided into a Northern and out-of-province group for statistical purposes, as the entire non-MUC region was quite wide. Thus, three groups were used in some analysis. Those were MUC, Northern and out of province, and remainder of non-MUC. This breakdown was decided as the Northern and out-of-province patients receive travel grants for medical costs, whereas the remainder of nonMUC patients were not subsidized. ${ }^{12-14}$ There are six pediatric surgeons at WCH. All six surgeons operated on patients in both treatment groups.

A patient was noted to have had a postoperative complication based on documentation in the electronic patient record. Minor complications may not have been captured if they are managed locally.

Any mention of the use of alternative follow-up modalities, such as telehealth or telephone calls, was noted. Additionally, reasons for not offering a follow-up appointment were captured. These reasons were qualitatively analyzed and grouped by theme.

\section{Statistical analysis and geomapping}

Descriptive statistics were performed. $\chi^{2}$ tests were performed on categorical variables. Microsoft Excel for Mac 2011 (V.14.7.3, 2010 Microsoft) was used for statistical analysis. A p value $<0.05$ was considered statistically significant. R Graphics software and Google Maps were used to perform geomapping of the data set through plotting each patient by postal code onto a map of Manitoba and its neighboring provinces and territories.

\section{RESULTS}

A total of 1506 patients were identified who were under 17 years of age and referred as an outpatient to the pediatric general surgery clinic at the WCH between 1 January 2016 and 31 December 2017. Of these patients, $723(48.0 \%)$ underwent an elective surgical procedure following their initial clinic visit. None of the eligible patients were excluded during the timeline of the study. There were no missing data.

Demographics are presented in table 1 along with the median distance travelled to clinic in kilometers by patient group. Figure 1 depicts the geographic distribution of the patient population using geomapping. There is a dense patient grouping in the MUC and its adjacent 
Table 1 Demographics by patient group $(n=723)$

\begin{tabular}{|c|c|c|}
\hline Variable & MUC (n=407) & Non-MUC (n=316) \\
\hline Distance travelled (km), median (range) & $8.9(0.9-22)$ & $119.5(20.3-1950)$ \\
\hline Gender (male), n (\%) & $245(60.2)$ & $196(62.0)$ \\
\hline Age at initial clinic visit, median (range) & 8 y $(18 \mathrm{~d}$ to $16 \mathrm{y})$ & 5.5 y ( 1 mon to $16 \mathrm{y})$ \\
\hline \multicolumn{3}{|l|}{ Referral source, n (\%) } \\
\hline Pediatrician & $230(56.5)$ & $92(29.1)$ \\
\hline Family doctor & $128(31.4)$ & $182(57.6)$ \\
\hline Dermatologist & $22(5.4)$ & $13(4.1)$ \\
\hline Emergency room physician & $18(4.4)$ & $13(4.1)$ \\
\hline Nurse practitioner & $7(1.7)$ & $9(2.8)$ \\
\hline General surgeon & $0(0)$ & $3(0.9)$ \\
\hline Gynecologist & $1(0.2)$ & $1(0.3)$ \\
\hline Nursing station & $0(0)$ & $1(0.3)$ \\
\hline Pediatric surgeon & $1(0.2)$ & $0(0)$ \\
\hline Registered midwife & $0(0)$ & $1(0.3)$ \\
\hline Unknown & $0(0)$ & $1(0.3)$ \\
\hline \multicolumn{3}{|l|}{ Geographic region, n (\%) } \\
\hline WRHA & 407 (100) & $0(0)$ \\
\hline Southern Health & $0(0)$ & $108(34.2)$ \\
\hline Interlake-Eastern & $0(0)$ & $87(27.5)$ \\
\hline Northern & $0(0)$ & $50(15.8)$ \\
\hline Prairie Mountain & $0(0)$ & $34(10.6)$ \\
\hline Northern Ontario & $0(0)$ & $19(6.0)$ \\
\hline Nunavut & $0(0)$ & $17(5.4)$ \\
\hline Saskatchewan & $0(0)$ & $1(0.3)$ \\
\hline
\end{tabular}

MUC, major urban center; WRHA, Winnipeg Regional Health Authority.

areas, with the remainder of the patient population scattered over a vast geographic area. The details of the surgical procedures summarized by patient group are provided in table 2.

\section{Follow-up appointments offered}

As seen in figure 2, within the MUC patient cohort, $72.7 \%$ of patients received a postoperative follow-up appointment $(\mathrm{n}=296 / 407)$, while only $60.8 \%$ of non-MUC patients were offered one $(n=192 / 316$, $\mathrm{p}<0.01)$. Within the non-MUC cohort, only $36.0 \%$ of the Northern and out-of-province patients received a postoperative follow-up appointment $(31 / 86)$, whereas $70.0 \%$ of the remaining non-MUC group were given one $(161 / 230)$. There is a statistically significant difference in the number of follow-up appointments offered to the Northern group compared with both the nonMUC and MUC cohorts $(p<0.001)$. With the separation of groups, there is no difference in follow-up appointments offered between the remaining non-MUC and MUC patients $(p=0.50)$. The reasons that patients do not have a follow-up appointment are provided in table 3 . The type of procedure performed significantly impacted follow-up offers (table 4). MUC patients who underwent several procedures, including dermatological excision, hernia repair, ingrown toenail, cholecystectomy, or a breast operation, were offered a significantly greater number of follow-up appointments compared with non-MUC patients who had the same procedures (table 4 ).

\section{Follow-up appointments attended}

MUC patients attended $88.5 \%$ of their follow-up appointments after their operation $(n=262 / 296)$. And there was 89.1\% follow-up attendance from non-MUC patients $(n=171 / 192)$, which was not statistically significant ( $p=0.84$, figure 2$)$. There remains no statistically significant difference in follow-up appointment attendance when the three patient cohorts are analyzed $(p=0.74$, 0.80 , and 0.85 , respectively). The type of surgical operation did not significantly impact follow-up compliance for the procedures listed in table 4 . There was no use of telehealth or video appointments as a means of alternative follow-up documented in our patient cohort. Four patients (3.3\%) received a telephone follow-up about their surgical pathology instead of an in-person clinic follow-up (table 3). 


\begin{tabular}{|c|c|c|}
\hline Variable & MUC $(n=407)$ & Non-MUC $(n=316)$ \\
\hline \multicolumn{3}{|l|}{ Type } \\
\hline Open & 359 (88.2) & $231(73.1)$ \\
\hline Laparoscopic & $31(7.6)$ & 65 (20.6) \\
\hline $\begin{array}{l}\text { Laparoscopic converted } \\
\text { to open }\end{array}$ & $13(3.2)$ & $8(2.5)$ \\
\hline Endoscopic & $5(1.2)$ & $13(4.1)$ \\
\hline Day surgery & $389(95.6)$ & $285(90.2)$ \\
\hline \multicolumn{3}{|l|}{ Procedure } \\
\hline Dermatological excisions & $158(38.8)$ & $65(20.6)$ \\
\hline Hernia repair & $80(19.7)$ & $93(29.4)$ \\
\hline Ingrown toenail & $39(9.6)$ & $21(6.6)$ \\
\hline Circumcision & $39(9.6)$ & $9(2.8)$ \\
\hline Orchidopexy & $20(4.9)$ & $23(7.3)$ \\
\hline Hydrocelectomy & $10(2.5)$ & $12(3.8)$ \\
\hline Line insertion/removal & $16(3.9)$ & $20(6.3)$ \\
\hline Cholecystectomy & $3(0.7)$ & $14(4.4)$ \\
\hline Endoscopy & $5(1.2)$ & $13(4.1)$ \\
\hline Tongue tie release & $7(1.7)$ & $4(1.3)$ \\
\hline \multicolumn{3}{|l|}{ Other } \\
\hline Abdominal & $5(1.2)$ & $10(3.2)$ \\
\hline Anorectal & $6(1.5)$ & $13(4.1)$ \\
\hline Ear, nose and throat & $2(0.5)$ & $2(0.6)$ \\
\hline Breast & $7(1.7)$ & $5(1.6)$ \\
\hline Diagnostic/exploratory & $3(0.7)$ & $7(2.2)$ \\
\hline Pilonidal & $5(1.2)$ & $1(0.3)$ \\
\hline Urogenital & $1(0.2)$ & $1(0.3)$ \\
\hline Thoracic & $1(0.2)$ & $3(0.9)$ \\
\hline
\end{tabular}

The data were shown as $\mathrm{n}(\%)$.

MUC, major urban center.

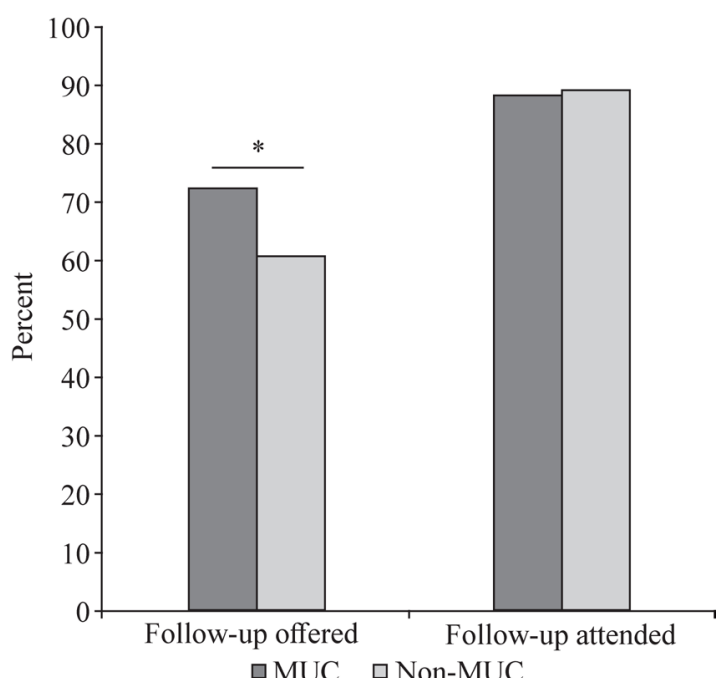

Figure 2 Comparison of follow-up appointments offered and attended by patient group. ${ }^{*} \mathrm{P}<0.05$. MUC, major urban center.
Table 3 Reason for not offering a follow-up appointment by patient group $(n=235)$

\begin{tabular}{lll}
\hline Reason & MUC (n=111) & Non-MUC (n=124) \\
\hline Unknown & $62(55.8)$ & $56(45.2)$ \\
\hline $\begin{array}{l}\text { Distance } \\
\quad \begin{array}{l}\text { Community health clinic to } \\
\text { see }\end{array}\end{array}$ & $0(0)$ & $15(25)$ \\
\hline $\begin{array}{l}\text { Family doctor to see } \\
\text { Surgeon wanted to see } \\
\text { patient }\end{array}$ & $6(19.4)$ \\
$\begin{array}{l}\text { None, no follow-up listed in } \\
\text { EPR }\end{array}$ & $33(29.7)$ & $22(17.7)$ \\
Follow-up not required & $15(13.5)$ & $10(8.1)$ \\
\hline \multicolumn{1}{l}{ Will call with pathology } & $1(0.9)$ & $3(2.4)$ \\
Follow-up with another service & $1(0.9)$ & $0(0)$ \\
\hline Follow-up as needed & $0(0)$ & $5(4.0)$ \\
\hline
\end{tabular}

The data were shown as $\mathrm{n}(\%)$.

EPR, electronic patient records; MUC, major urban center.

\section{Postoperative complications}

Forty patients from the MUC developed a postoperative complication $(9.8 \%)$, along with 29 non-MUC patients $(9.2 \%) \quad(p=0.78)$. The postoperative complications are shown in table 5 .

\section{DISCUSSION}

With the recent centralization of healthcare in Canada, many patients and their families must travel considerable distances to access specialized care. Our results confirm the immense distance travelled by some patients and their families. However, what was unknown was whether families from out of town were offered the same rates of follow-up, and if they were able to attend their appointments. Non-MUC patients were offered fewer follow-up appointments; however, the attendance rates were the same. There was no difference in complications noted, suggesting that reduced follow-up might not have diminished patient care. Severity of illness was not captured during data collection. Thus, it was unknown as to whether or not follow-up differed depending on the severity of the condition that the patient was referred for. Our study focused on patients having surgery with an anticipated shorter length of stay ( $<48$ hours). It did not include patients with major neonatal surgical conditions and congenital malformations for whom we would routinely offer follow-up. We sought to assess if patients from nearby and far away having undergone smaller procedures had a difference in complications and in follow-up compliance. Follow-up by the surgeon for these conditions/procedures could be eliminated, thus saving the healthcare system, and patients and their families, valuable time and money.

The indication for offering patients a follow-up appointment in our cohort was not documented in the medical records. Routine criteria for the need of a 
Table 4 Follow-up offered and follow-up compliance by surgical procedure and patient group

\begin{tabular}{|c|c|c|c|c|}
\hline \multirow[b]{2}{*}{ Procedure } & \multicolumn{2}{|l|}{ MUC n (\%) } & \multicolumn{2}{|c|}{ Non-MUC n (\%) } \\
\hline & Offered & Compliance & Offered & Compliance \\
\hline Dermatological excisions & $98(62.0)^{\star}$ & $85(86.7)$ & $28(43.1)$ & $23(82.1)$ \\
\hline Hernia repair & $74(92.5)^{\star}$ & 69 (93.2) & $68(73.1)$ & $61(89.7)$ \\
\hline Ingrown toenail & $29(74.3)^{\star}$ & $21(72.4)$ & $10(47.6)$ & $8(80.0)$ \\
\hline Circumcision & 33 (84.6) & 31 (93.9) & $6(66.7)$ & $6(100.0)$ \\
\hline Orchidopexy & $18(90.0)$ & $17(94.4)$ & $22(95.6)$ & $21(95.4)$ \\
\hline Hydrocelectomy & $9(90.0)$ & $9(100.0)$ & $11(91.7)$ & $11(100.0)$ \\
\hline Line insertion/removal & $4(25.0)$ & $4(100.0)$ & $5(25.0)$ & $5(100.0)$ \\
\hline Cholecystectomy & $3(100.0)^{*}$ & $2(66.7)$ & $4(28.6)$ & $3(75.0)$ \\
\hline Endoscopy & $4(80)$ & $3(75.0)$ & $9(69.2)$ & $8(88.9)$ \\
\hline Tongue tie release & $0(0)$ & $0(0)$ & $0(0)$ & $0(0)$ \\
\hline \multicolumn{5}{|l|}{ Other } \\
\hline Abdominal & $3(60)$ & $3(100.0)$ & $7(70.0)$ & $6(85.7)$ \\
\hline Anorectal & $4(66.7)$ & $4(100.0)$ & 10 (76.9) & $10(100.0)$ \\
\hline Ear, nose and throat & $2(100.0)$ & $2(100.0)$ & $2(100.0)$ & $2(100.0)$ \\
\hline Breast & $6(85.7)^{\star}$ & $5(83.3)$ & $1(20.0)$ & $1(100.0)$ \\
\hline Diagnostic/exploratory & $2(66.7)$ & $0(0)$ & $5(71.4)$ & $3(60.0)$ \\
\hline Pilonidal & $5(100.0)$ & $5(100.0)$ & $1(100.0)$ & $1(100.0)$ \\
\hline Urogenital & $1(100.0)$ & $1(100.0)$ & $1(100.0)$ & $0(0)$ \\
\hline Thoracic & $1(100.0)$ & $1(100.0)$ & $2(66.7)$ & $2(100.0)$ \\
\hline
\end{tabular}

${ }^{*}$ Statistically significant if $\mathrm{p}<0.05$. $\mathrm{P}$ value were obtained by $\chi^{2}$ test based on the differences of follow-up offered and follow-up compliance between the MUC and non-MUC group.

MUC, major urban center.

follow-up visit are not currently in place (see table 3). Offering a follow-up appointment is a decision made based on surgeon preference and experience, taking into consideration the complexity of the procedure and individual patient factors. Follow-up may in fact not be required for routine operations. And surgeons are not mandating follow-up. Therefore, they are accepting decreased personal remuneration over patient inconvenience, while ensuring patient safety. Patients who were deemed to not require a follow-up at WCH were advised instead to follow-up with their referring physician or local healthcare provider as needed. However, it is currently unknown if most referring physicians are comfortable with managing postoperative follow-up of simple pediatric surgical conditions given appropriate instructions.

\begin{tabular}{|c|c|c|}
\hline Variable & MUC $(n=40)$ & Non-MUC $(n=29)$ \\
\hline \multicolumn{3}{|l|}{ Type, n (\%) } \\
\hline Wound infection/bleeding & $31(77.5)$ & $19(65.5)$ \\
\hline Recurrence & $8(20)$ & $7(24.1)$ \\
\hline Need for further surgery & $1(2.5)$ & $1(3.4)$ \\
\hline Other & $0(0)$ & $2(6.9)$ \\
\hline Deaths $(n=723)$ & 0 & 0 \\
\hline
\end{tabular}

MUC, major urban center.
A study from Alberta, Canada, found that overall 58\% of pediatric general surgery patients attended a postoperative follow-up appointment. ${ }^{15}$ Patients living closer to the hospital had an approximately twofold greater chance of attending follow-up, and those farther away had a $60 \%$ decreased likelihood of attending, which is not in keeping with our findings. Often, postoperative complication rates are low and may be managed by local primary healthcare providers without the need for specialist assessment, as found in our study, as well as in the Alberta study. ${ }^{15}$

Pediatric urology patients in Quebec, Canada, travel a mean of $70 \mathrm{~km}$ one way for their clinic appointments, but those from farther away can travel in excess of 1000 $\mathrm{km} .{ }^{16}$ Provincial monetary reimbursement is available for travel greater than $200 \mathrm{~km}$ for medical care. Our patient population can also receive subsidized medical transportation for care unavailable in their community, or if their required specialist care is not available within 100 $\mathrm{km}$ from their home. ${ }^{12-14}$ From our records, the number of patients in our cohort that use available provincial monetary support for their medical travel is unknown but is likely to include all of our non-MUC patients from Nunavut, Northern Ontario, Northern Manitoba, and some from the Interlake-Eastern geographic region of Manitoba. However, costs still arise in excess of the amount funded and do not cover days of missed school and work. 
One recent Canadian study found that $75 \%$ of families had one or more parents absent from half a day or more of work to attend their child's surgical appointment. ${ }^{8}$ Gimon et al found that postoperative follow-up visits for pediatric surgery patients after common surgeries were likely of little need and posed great financial burdens to patients, families, and the system. ${ }^{15}$

Surgeons and their patients could use other methods of follow-up to document complications and to track patient outcomes. One possible solution for reducing financial costs and school and employment absenteeism is telemedicine or e-medicine follow-up options, ${ }^{816-18}$ although minimal research exists with respect to telemedicine in pediatric surgery. ${ }^{16}$ In other surgical specialties using telemedicine, patient's families and surgeons have reported satisfaction with the system along with a decreased financial burden. ${ }^{8}$ Telehealth and e-consult are both available for use by physicians in Manitoba; however, there is no mention of their use in our studied population. This is likely due to patient preference for in-person follow-up appointments, and inconveniences associated with telehealth use in Manitoba, such as requiring a special room and equipment, and to lack of remuneration for surgeons. However, in examining our data, there were no unexpected findings or anything else of intrinsic value to the patient or family that arose during our in-person follow-up appointments, thus questioning the need for these appointments following an uncomplicated and short-duration surgery.

Another solution is the creation of 'outreach' clinics, where the surgeon travels to remote communities to provide follow-up in person. ${ }^{19}$ There is scant Canadian literature with regard to surgical outreach clinics. Bernstein describes his experience in setting up and running a rural neurosurgery outreach clinic. He identified a need due to the large distances between surgical specialties and the communities they served. ${ }^{19}$ Bernstein highlights the following advantages for the surgeon, patients, and local physicians: providing valuable care for underserviced areas, networking in these areas, and avoiding long trips to appointments, which directly results in patient cost savings and allows local physicians to provide this group of patients with the specialist care they need. ${ }^{19}$

A British systematic review focused on outreach clinics in primary care,${ }^{20}$ highlighting improved patient experiences and access to care in the outreach clinic setting, along with a greater patient preference for outreach clinics compared with the hospital-based equivalent. O'Brien $e t$ al ran a randomized controlled trial looking at specialist outreach clinics in the field of orthodontics and similarly found a higher patient preference towards attending an appointment at an outreach clinic. ${ }^{21}$ Lastly, Haynes et al found that offering an outreach clinic for cataract surgery provided patients with a shorter travel time and less costly journey, along with significantly greater satisfaction. ${ }^{22}$ These studies have found similar advantages and highlights of outreach clinics across various medical and surgical specialties. However, outreach clinics may result in an increase in physician workload and increased physician-associated financial costs. ${ }^{19}$

Along with telehealth and e-consult, remote follow-up was not used in our patient cohort. However, given their advantages and the desire from patients who must travel great distances to continue seeking ongoing care, there are plans to implement them as follow-up modalities for use by our pediatric surgeons. The use of telemedicine and remote follow-up would also be recommended for chronically ill children in order to increase patient satisfaction and ensure a high level of compliance. Of note, four of our patients $(3.3 \%)$ received a phone call regarding their surgical pathology as it was deemed that an in-person follow-up was not required (table 3). Currently, telephone calls are not commonly used as another means of follow-up for patients living farther from our center, nor is email communication. However, a study by McVay et al at the Arkansas Children's Hospital demonstrated that postoperative follow-up performed using a structured telephone protocol was in fact a positive substitute for in-person follow-up. ${ }^{23}$ They implemented their protocol in select pediatric surgical procedures, such as herniorrhaphy, non-perforated laparoscopic appendectomy, circumcision, dermatological excisions, laparoscopic cholecystectomy, and ingrown toenails. They noted multiple advantages of this follow-up modality, namely not having to miss school and work for travel for an appointment that was usually straightforward and did not yield anything of significance, decreased costs and use of healthcare services, and a decline in clinic no-show rates. This especially allows for more time being spent on new consults or complicated cases. Their telephone follow-up was found to be favored with $90 \%$ family satisfaction, and none of them asked for an in-person visit. ${ }^{23}$ The use of telephone follow-up in pediatric inguinal hernia repair had previously been documented as practical and efficient. ${ }^{24}$ Furthermore, Fischer et al compared rates of postoperative follow-up between in-person visits and telephone calls following select pediatric general surgery procedures and found better rates in the phone call group, along with a $93 \%$ satisfaction. ${ }^{25}$ A reduction in institutional costs, along with family and patient financial savings, was documented.$^{25}$ Telephone follow-up calls are therefore an effective alternative modality that will allow for family-centered patient care and appropriate follow-up attendance.

Telemedicine and remote postoperative follow-up have become very important modalities during the recent COVID-19 pandemic. As a result, telemedicine, including videoconference calls, which allow the surgical provider the ability to perform visual wound inspections, is being used more often in our center, and will likely continue to be used.

Limitations to this study are its retrospective nature and the lack of complete documentation within the pediatric surgical charts. Multiple patients had a postoperative follow-up appointment with no documented correspondence; as such, their postoperative course and 
potential complications were unknown. Many patients who were not offered a postoperative follow-up appointment did not have documentation with regard to why. Thus, it is unknown if this was due to distance and travel, surgeon or patient preference, or the type of procedure the patient underwent.

\section{CONCLUSIONS}

Patients living farther from a pediatric surgical center are not offered the same number of follow-up appointments as their urban counterparts. The need and appropriateness for follow-up after routine operations should be assessed further, so that patients, families, and the system can save time and costs if they are deemed unnecessary. Based on our low complication rate, possibly no follow-up is needed for common pediatric surgeries, even in MUC patients. The overall number of follow-ups being performed could be decreased.

Telemedicine and remote follow-up are underused approaches, which can be incorporated when follow-up is needed to improve patient care, to reduce costs, and to reduce employment and school absenteeism for patients and their families. Outreach clinics are also a possibility, while being mindful of surgeon availability. Surveys of patients, their caregivers, primary care providers, and pediatric surgeons are being performed to evaluate their thoughts and opinions on pediatric surgery follow-up and on the need for routine in-person follow-up. Their willingness to decrease routine follow-ups, satisfaction with the current clinic follow-up format, and interest in follow-up being provided by alternative modalities will be assessed and included in postoperative care pathways.

Acknowledgements We would like to thank Matthew Levesque for his assistance with geomapping, and Janet Rowe for her assistance with editing the manuscript.

Contributors WME contributed to conceptualization, data curation, formal analysis and writing. SAC performed conceptualization, formal analysis and writing.

Funding The authors have not declared a specific grant for this research from any funding agency in the public, commercial or not-for-profit sectors.

Map disclaimer The depiction of boundaries on this map does not imply the expression of any opinion whatsoever on the part of BMJ (or any member of its group) concerning the legal status of any country, territory, jurisdiction or area or of its authorities. This map is provided without any warranty of any kind, either express or implied.

Competing interests None declared.

Patient consent for publication Not required.

Ethics approval This study was approved by the University of Manitoba Health Research Ethics Board (REB HS21685 (H2018:134)).

Provenance and peer review Not commissioned; externally peer reviewed.

Data availability statement All data relevant to the study are included in the article or uploaded as supplementary information. Nothing further to add.

Open access This is an open access article distributed in accordance with the Creative Commons Attribution Non Commercial (CC BY-NC 4.0) license, which permits others to distribute, remix, adapt, build upon this work non-commercially, and license their derivative works on different terms, provided the original work is properly cited, appropriate credit is given, any changes made indicated, and the use is non-commercial. See: http://creativecommons.org/licenses/by-nc/4.0/.
ORCID iD

Meagan E Wiebe http://orcid.org/0000-0002-8640-3446

\section{REFERENCES}

1 Van Aerde J. Has regionalization of the Canadian health system contributed to better health? Canadian Journal Of Physician Leadership 2016;2:65-70.

2 Skarsgard ED. Networks in Canadian paediatric surgery: time to get connected. Paediatr Child Health 2006;11:15-18.

3 Kelly C, Hulme C, Farragher T, et al. Are differences in travel time or distance to healthcare for adults in global North countries associated with an impact on health outcomes? A systematic review. BMJ Open 2016;6:e013059.

4 Statistics Canada, Geography Division. Geography. Available: https://www150.statcan.gc.ca/n1/pub/11-402-x/2012000/chap/geo/ geo-eng.htm [Accessed 5 Aug 2019].

5 The Canadian Pediatric Surgery Network. Participating sites. 2019 Canadian pediatric surgery network (CAPSNET). Available: http://www.capsnetwork.org/portal/About/ParticipatingSites.aspx [Accessed 21 Jul 2019].

6 Statistics Canada. Canada (table 1.7). Census Profile. 2016 Census. Statistics Canada Catalogue no 98-316-X2016001. Ottawa. Available: https://www12.statcan.gc.ca/census-recensement/2016/ ref/dict/geo049a-eng.cfm [Accessed 21 Jul 2019].

7 Haynes R. Geographical access to healthcare. In: Guilliford M, Morgain M, eds. Access to healthcare. London: Routledge, 2003: 13-35.

8 Bator EX, Gleason JM, Lorenzo AJ, et al. The burden of attending a pediatric surgical clinic and family preferences toward telemedicine. J Pediatr Surg 2015;50:1776-82.

9 Canadian Pediatric Endocrine Group. Locum position - Winnipeg Children's Hospital, University of Manitoba. Available: https://cpeggcep.net/forums/general-cpeg-forum/jobs-locum-positions/locumposition-winnipeg-children\%E2\%80\%99s-hospital [Accessed $21 \mathrm{Jul}$ 2019].

10 RD Services WRHA Service Directory. Available: http://www.wrha. $\mathrm{mb} . c a /$ extranet/nutrition/files/RDServicesWRHAServiceDirectory.pdf [Accessed $21 \mathrm{Jul} 2019$ ]

11 WorldAtlas. The largest and smallest Canadian Provinces/Territories by area. Available: https://www.worldatlas.com/articles/the-largestand-smallest-canadian-provinces-territories-by-area.html [Accessed 5 Aug 2019].

12 Manitoba Health, Seniors and Active Living. Northern patient transportation program. Available: https://www.gov.mb.ca/health/ ems/nptp.html [Accessed 15 Jul 2019].

13 Nunavut Department of Health. Medical travel. Available: https:// www.gov.nu.ca/health/information/medical-travel [Accessed $15 \mathrm{Jul}$ 2019].

14 Ontario Ministry of Health and Long-Term Care. Northern health travel grants. Available: http://www.health.gov.on.ca/en/public/ publications/ohip/northern.aspx [Accessed $15 \mathrm{Jul}$ 2019].

15 Gimon T, Almosallam O, Lopushinsky S, et al. Optimizing postoperative follow-up in pediatric surgery (OFIPS). J Pediatr Surg 2019;54:1013-8.

16 Otis-Chapados S, Coderre K, Bolduc S, et al. Evaluating the distance travelled for urological pediatric appointments. Can Urol Assoc J 2019;13:391-4.

17 MBTelehealth. About MBTelehealth. Available: http://www mbtelehealth.ca/abt-about.html [Accessed 15 Jul 2019].

18 MBTelehealth. eConsult (store and forward). Available: http://www. mbtelehealth.ca/svs-str-frwrd.html [Accessed 15 Jul 2019].

19 Bernstein M. Surgical outreach clinics in Canada: one neurosurgeon's experience. Can J Surg 2004;47:25-8.

20 Powell J. Systematic review of outreach clinics in primary care in the UK. J Health Serv Res Policy 2002;7:177-83.

21 O'Brien K, Mattick R, Mandall N, et al. Are specialist outreach clinics for orthodontic consultation effective? a randomised controlled trial. Br Dent J 2001;191:203-7.

22 Haynes R, Gale S, Mugford M, et al. Cataract surgery in a community hospital outreach clinic: patients' costs and satisfaction. Soc Sci Med 2001:53:1631-40.

23 McVay MR, Kelley KR, Mathews DL, et al. Postoperative follow-up: is a phone call enough? J Pediatr Surg 2008;43:83-6.

24 Koulack J, Fitzgerald P, Gillis DA, et al. Routine inguinal hernia repair in the pediatric population: is office follow-up necessary? $\mathrm{J}$ Pediatr Surg 1993;28:1185-7.

25 Fischer K, Hogan V, Jager A, et al. Efficacy and utility of phone call follow-up after pediatric general surgery versus traditional clinic follow-up. Perm J 2015;19:11-14. 